\title{
p38 inhibitor inhibits the apoptosis of cowanin-treated human colorectal adenocarcinoma cells
}

\author{
NITTIYA CHOWCHAIKONG ${ }^{1}$, SIRINUN NILWARANGKOON $^{1}$, SURAT LAPHOOKHIEO $^{2}$, \\ CHANTRA TANUNYUTTHAWONGSE ${ }^{1}$ and RAMIDA WATANAPOKASIN ${ }^{1}$
}

\author{
${ }^{1}$ Department of Biochemistry, Faculty of Medicine, Srinakharinwirot University, Bangkok 10110; \\ ${ }^{2}$ Department of Chemistry, Faculty of Science, Mae Fah Luang University, Muang, Chiang Rai 57100, Thailand
}

Received September 11, 2017; Accepted March 16, 2018

DOI: 10.3892/ijo.2018.4353

\begin{abstract}
Colorectal cancer, which is the third most common type of cancer diagnosed in both men and women, is the leading cause of cancer-related deaths worldwide. Cowanin is a pure compound extracted from Garcinia cowa Roxb., a tree species present in Thailand, Malaysia and Myanmar. The crude extract has been demonstrated to have antitumor activity, inflammation induction, antibacterial activity, anti-inflammatory activity and antimalarial activity. In the present study, the effects of cowanin on apoptosis induction and on the apoptosis-related and mitogen-activated protein kinase (MAPK) pathways were investigated in the LoVo human colorectal cancer cell line. The cytotoxicity of cowanin in LoVo cells was determined by MTT assay. Hoechst 33342 and JC-1 staining were used to determine nuclear morphological changes and mitochondrial membrane potential, respectively. The expression levels of BCL2 apoptosis regulator (Bcl-2) family, MAPK and AKT serine/threonine kinase 1 (Akt) pathway proteins following cowanin treatment were determined by western blot analysis. The results demonstrated that cowanin inhibited cell proliferation and induced cell death via the apoptosis pathway. Cowanin treatment increased BCL2 associated X (Bax) and decreased Bcl-2 expression. In addition, cowanin activated caspase-9, -7 and poly-ADP-ribose-polymerase expression. Furthermore, cowanin decreased the levels of phosphorylated extracellular signal-regulated kinase (p-ERK), p-Akt, p-3-phosphoinositide-dependent protein kinase-1, while it increased p-p38 expression, thus resulting in the induction of apoptosis. In conclusion, cowanin inhibited cell proliferation and induced apoptosis of LoVo cells via the MAPK and Akt signaling pathways. Notably, inhibition of p38 by using a p38 inhibitor (SB203580) prevented the cowanin-induced
\end{abstract}

Correspondence to: Professor Ramida Watanapokasin, Department of Biochemistry, Faculty of Medicine, Srinakharinwirot University, 114 Sukhumvit 23, Bangkok 10110, Thailand

E-mail: ramidaw@g.swu.ac.th; ramidawa@yahoo.com

Key words: cowanin, colorectal cancer, apoptosis, mitogen-activated protein kinase, p38 inhibitor apoptosis in LoVo cells. These results suggested that cowanin may be a potential candidate for the treatment of colorectal cancer and provided important information on the molecular mechanisms underlying its antitumor activity.

\section{Introduction}

Colorectal cancer is the third most common cancer diagnosed in both men and women (1) and the third leading cause of cancer-related deaths worldwide (2). In Thailand, colorectal cancer is one of the most common malignancies in men and women. A high incidence of colorectal cancer is present in the urban region on the western part of Thailand (3). A preliminary factor contributing to the incidence of colorectal cancer is diet, including eating red meat, alcohol, low physical activity and low vegetable consumption. In addition, family history is another important factor (4).

Apoptosis is a process of programmed cell death that occurs in multicellular organisms. Apoptosis is an attractive target in cancer therapy. Apoptosis can be induced via two signaling pathways: the intrinsic mitochondria pathway and the extrinsic death receptor pathway. The intrinsic apoptotic pathway is initiated when an injury occurs within the cell and it is activated by intracellular signals from mitochondria. Dimerization of BCL2 associated X (Bax)/BCL1 antagonist/ killer 1 (Bak) results in a proapoptotic protein complex that reduces the activity of BCL2 apoptosis regulator (Bcl-2), subsequently regulating the permeability of the mitochondrial membrane. Activation of Bax results in the release of cytochrome $c$ from the mitochondrial membrane, which then activates caspase- 9 and caspase-3/7 to induce apoptosis in cancer cells. The extrinsic apoptotic pathway is initiated through the binding of cell surface death receptors with ligands, such as TNF-related apoptosis-inducing ligand (TRAIL), and it is activated by caspase- 8 and caspase $-3 / 7$ to induce apoptosis in cancer cells (5-8).

Mitogen-activated protein kinase (MAPK) pathways have a role in controlling crucial cellular processes, including growth, proliferation, differentiation, migration, and apoptosis. MAPK pathways contain three kinases: extracellular signal-regulated kinase (ERK) 1/2, c-Jun N-terminal kinase (JNK) $1 / 2$, and MAPK14 (also known as p38) (9). The p38 MAPK has an important role in the regulation of cell survival 
and cell death in various types of cancer (10). Usually, p38 is activated by inflammatory cytokines, heat shock and ultraviolet light, mediating growth arrest and inducing apoptosis (11). Previous studies have reported that $\mathrm{p} 38$ activates apoptosis by generating reactive oxygen species (ROS) (12). In addition, p38 induces apoptosis by upregulating Bax and downregulating the ERK and Akt survival pathways (13). Of note, the p38 MAPK inhibitor SB203580 represents one of the most widely used therapies for the treatment of inflammation (14).

Garcinia cowa Roxb. (Guttiferae) commonly known as 'Cha-muang', is a tropical tree species present in Malaysia, Myanmar and Thailand (15). Multiple parts of G. cowa are used in traditional folk medicine for various purposes. The bark, the latex and the root are used as antipyretics $(16,17)$. Crude extract from leaves exhibits antitumor activity (18) and inflammation induction (19). The fruits and leaves have been reported to improve blood circulation, and are used as an expectorant for the treatment of cough, for the treatment of indigestion and as a laxative (15).

Cowanin is a xanthone that is extracted from stem bark of G. cowa (20). Cowanin extracted from fruits has been reported to have an antibacterial activity against Staphylococcus aureus and Methicillin-resistant Staphylococcus aureus (MRSA) (15). Cowanin has demonstrated antimalarial activity against Plasmodium falciparum with $\mathrm{IC}_{50}$ values of $1.5-3.0 \mu \mathrm{g} / \mathrm{ml}(20)$, anti-inflammatory activity (21), and it is active against MCF-7 breast cancer cells (22). In addition, cowanin extracted from leaves was evaluated for cytotoxicity against $\mathrm{NCl}-\mathrm{H} 187, \mathrm{~KB}$ and MCF-7 cell lines with $\mathrm{IC}_{50}$ values of 3.87-8.58, 6.43-15.43 and $10.59-21.38 \mu \mathrm{g} / \mathrm{ml}$, respectively (23). However, the effects of cowanin on inducing apoptosis in human colorectal cancer cells have not yet been reported.

The present study aimed to investigate whether cowanin could induce apoptosis and inhibit growth in a human colorectal cancer cell line. First, the cytotoxicity of cowanin in LoVo cells was determined by MTT assay. Then the mechanism of apoptosis was detected by examining morphological changes such as cell shrinkage, membrane blebbing, and chromatin condensation, and by determining the expression of caspase, Bcl-2 family, MAPK and Akt signaling pathway proteins. In addition, the effect of cowanin in combination with a p38 inhibitor was assessed. The data demonstrated a significant anticancer effect of cowanin in colorectal cancer cells.

\section{Materials and methods}

Chemicals. Hoechst 33342, fetal bovine serum (FBS), MTT, 5,5',6,6'-tetrachloro-1,1',3,3'-tetraethyl-imidacarbocyanine iodide (JC-1) and phenylmethylsulphonyl fluoride (PMSF) were purchased from Sigma-Aldrich (Merck KGaA, Darmstadt, Germany). RPMI-1640 medium was purchased from Gibco; (Thermo Fisher Scientific, Inc., Waltham, MA, USA). DMSO and Guava Cell Cycle reagent for cell cycle analysis was purchased from Merck KGaA. MAPK kinase 1 (also known as MEK1)/MAPK kinase 2 (also known as MEK2) inhibitor (U0126), p38 inhibitor (SB203580), and primary antibodies [Bax, 1:1,000 (Cat. no. 2772); Bcl-2, 1:1,000 (Cat. no. 2876); Bcl-xL, 1:1,000 (Cat. no. 2764); caspase-9, 1:1,000 (Cat. no. 9502P); caspase-7, 1:1,000 (Cat. no. 9492);
poly-ADP-ribose-polymerase (PARP), 1:1,000 (Cat. no. 9532); ERK, 1:1,000 (Cat. no. 4695); p-ERK, 1:1,000 (Cat. no. 4370); p38 1:1,000 (Cat. no. 9212); p-p38, 1:1,000 (Cat. no. 4511); Akt, 1:1,000 (Cat. no. 4691); p-Akt (Ser473), 1:1,000 (Cat. no. 4060); phosphorylated 3-phosphoinositide-dependent protein kinase-1 (p-PDK1) (Ser241), 1:1,000 (Cat. no. 3061); and $\beta$-actin, 1:1,000 (Cat. no. 4967)] and secondary antibodies [anti-rabbit IgG, HRP-linked antibody 1:25,000 (Cat. no. 7074) and anti-mouse IgG, HRP-linked antibody 1:25,000 (Cat. no. 7076)] were all purchased from Cell Signaling Technology, Inc. (Danvers, MA, USA). Cowanin (chemical structure illustrated in Fig. 1A), a bioactive agent extracted from the $G$. cowa plant (24), was obtained from Associate Professor Surat Laphookhieo, Mae Fah Luang University (Muang, Thailand).

Cell culture. The human colorectal cancer cell line LoVo and Monkey Kidney (SV 40 transformed) cell line COS-7 was obtained from the American Type Culture Collection (ATCC; Manassas, VA, USA). LoVo cells were maintained as a monolayer in PRMI-1640 supplemented with 10\% FBS, $100 \mathrm{U} / \mathrm{ml}$ penicillin and $100 \mu \mathrm{g} / \mathrm{ml}$ streptomycin at $37^{\circ} \mathrm{C}$ in a humidified atmosphere of $5 \% \mathrm{CO}_{2}$. COS-7 cells were maintained as a monolayer in Dulbecco's modified Eagle's medium supplemented with $10 \%$ FBS, $100 \mathrm{U} / \mathrm{ml}$ penicillin and $100 \mu \mathrm{g} / \mathrm{ml}$ streptomycin at $37^{\circ} \mathrm{C}$ in a humidified atmosphere of $5 \% \mathrm{CO}_{2}$.

Evaluation of proliferation potential (MTT assay). Cell proliferation was determined by MTT assay. In brief, LoVo cells were seeded at $0.5 \times 10^{4}$ cells/well in a 96-well plate followed by incubation at $37^{\circ} \mathrm{C}$ for $24 \mathrm{~h}$, then treated with cowanin at various concentrations $(5,10,15$ and $20 \mu \mathrm{g} / \mathrm{ml})$. The control group was treated with vehicle alone (0.5\% DMSO). After incubation for 3, 6, 9, 12 and $24 \mathrm{~h}, 0.5 \mathrm{mg} / \mathrm{ml}$ MTT solution was added to each well and the plate was further incubated at $37^{\circ} \mathrm{C}$. The supernatant was removed and DMSO was added to each well to solubilize the purple formazan crystals. The absorbance was measured at $570 \mathrm{~nm}$ using a microplate reader (Multiskan EX; Thermo Labsystems, Helsinki, Finland). The $\mathrm{IC}_{50}$ (50\% inhibitory concentration) value was calculated using GraphPad Prism 3.03 (GraphPad Software, Inc., La Jolla, CA, USA).

Detection of nuclear morphology by Hoechst 33342 staining. LoVo cells were seeded at a density of $3 \times 10^{5}$ cells/well in a $35-\mathrm{mm}$ dish and treated with $15 \mu \mathrm{g} / \mathrm{ml}$ cowanin for 3, 6, 9 and $12 \mathrm{~h}$. Cells were washed with PBS and then stained with $5 \mu \mathrm{g} / \mathrm{ml}$ of Hoechst 33342 for $30 \mathrm{~min}$. Apoptotic cells were observed under a fluorescence microscope.

Detection of mitochondrial membrane potential $(\Delta \Psi m)$. LoVo cells were seeded at $3 \times 10^{5}$ cells/well in a $35-\mathrm{mm}$ dish for $24 \mathrm{~h}$, then treated with $15 \mu \mathrm{g} / \mathrm{ml}$ cowanin for 3, 6,9 and $12 \mathrm{~h}$. Cells were stained with $5 \mu \mathrm{g} / \mathrm{ml} \mathrm{JC}-1$ at $37^{\circ} \mathrm{C}$ for $10 \mathrm{~min}$, and observed under a fluorescence microscope.

Cell cycle analysis. LoVo cells were seeded at $1 \times 10^{6}$ cells/well in a $60-\mathrm{mm}$ dish and allowed to grow for $24 \mathrm{~h}$ at $37^{\circ} \mathrm{C}$. For cowanin treatment alone, cells were treated with $15 \mu \mathrm{g} / \mathrm{ml}$ cowanin for 24 and $48 \mathrm{~h}$. For the combination treatment, cells were incubated with $10 \mu \mathrm{M}$ of SB203580 for $1 \mathrm{~h}$ and then with 
A<smiles>[R]c1c(O)c([R])c2oc3cc(O)c(OC)c([R])c3c(=O)c2c1O</smiles>
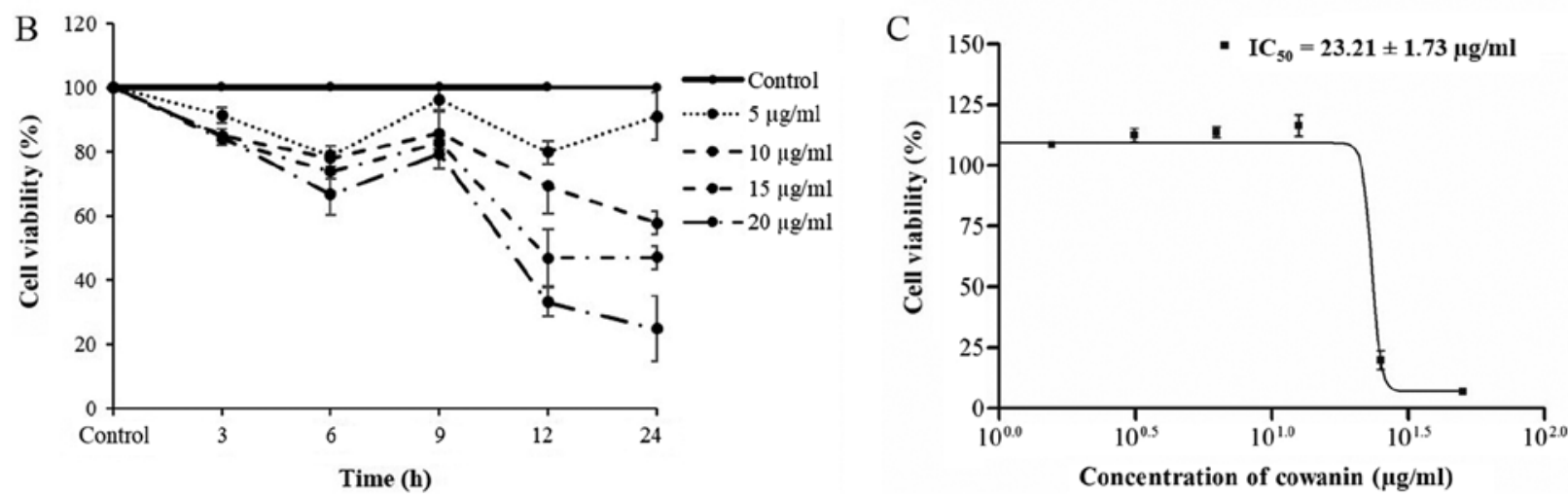

Figure 1. Effects of cowanin on cell viability in LoVo cells. (A) The chemical structure of cowanin extracted from Garcinia cowa Roxb. (B) Time and dose-dependent effect on LoVo cells treated with different concentrations of cowanin and for various time-points. (C) Effect of cowanin on cell viability of normal COS-7 cells. Results are mean values \pm standard deviation of three independent experiments performed in triplicate.

$15 \mu \mathrm{g} / \mathrm{ml}$ cowanin for 24 and $48 \mathrm{~h}$. The control group was treated with DMSO. The cells were washed with ice cold PBS once and fixed with $70 \%$ ethanol at $4^{\circ} \mathrm{C}$ for $30 \mathrm{~min}$. Then, the cells were stained with propidium iodide (PI), according to the manufacturer's instructions (Guava Cell Cycle reagent). The DNA content was analyzed using the Guava EasyCyte flow cytometer and GuavaSoft software (Merck KGaA).

Cell surface phosphatidyl-serine determination. LoVo cells were seeded at $1 \times 10^{6}$ cells/well in a $60-\mathrm{mm}$ dish and allowed to grow for $24 \mathrm{~h}$ at $37^{\circ} \mathrm{C}$. For cowanin treatment alone, cells were treated with $15 \mu \mathrm{g} / \mathrm{ml}$ cowanin for 12 and $24 \mathrm{~h}$. For the combination treatment, cells were incubated with $10 \mu \mathrm{M}$ of SB203580 for $1 \mathrm{~h}$ and then with $15 \mu \mathrm{g} / \mathrm{ml}$ cowanin for 12 and $24 \mathrm{~h}$. The control group was treated with DMSO. Following treatments, the cells were washed with ice cold PBS once and stained with Guava Nexin reagent (Merck KGaA), according to the manufacturer's instructions. The stained cells were analyzed for cell surface phosphatidyl-serine content on a Guava EasyCyte flow cytometer with GuavaSoft software (Merck KGaA).

Western blot analysis. LoVo cells were seeded at $2 \times 10^{5}$ cells/well in a $35-\mathrm{mm}$ dish followed by incubation at $37^{\circ} \mathrm{C}$ for $24 \mathrm{~h}$ and then treated with $15 \mu \mathrm{g} / \mathrm{ml}$ cowanin for $3,6,9,12,18$ and $24 \mathrm{~h}$. Cells were lysed with RIPA lysis buffer $(50 \mathrm{mM}$ Tris- $\mathrm{HCl}$ pH 7.5, 5 mM EDTA, $250 \mathrm{mM} \mathrm{NaCl}, 0.5 \%$ Triton X-100) and complete mini protease inhibitor cocktail (Roche Diagnostics $\mathrm{GmbH}$, Mannheim, Germany). Total protein concentration was determined by a protein assay kit (Bio-Rad Laboratories, Inc., Hercules, CA, USA). For immunoblotting, total protein from each sample was subjected to 8-12\% SDS-PAGE and transferred onto a polyvinylidene fluoride membrane using a Mini Trans-Blot Cell (Bio-Rad Laboratories, Inc.). The membrane was blocked with $5 \%$ non-fat milk powder $(\mathrm{w} / \mathrm{v})$ at room temperature, and then incubated with primary antibodies at $4^{\circ} \mathrm{C}$ overnight. Following washing, the membrane was incubated with secondary antibody conjugated with horseradish peroxidase (anti-rabbit or anti-mouse) at room temperature. $\beta$-actin was used as an internal control to monitor equal protein loading and transfer of proteins from the gel to the membranes. Immunoreactive protein bands were detected using an enhanced chemiluminescence reagent (Merck $\mathrm{KGaA}$ ) and detected under a chemiluminescent imaging system (GeneGnome Gel Documentation; Synoptics Ltd., Cambridge, UK).

Statistical analysis. All data presented were obtained from at least three independent experiments and are presented as mean \pm standard deviation. Differences between groups were assessed by one-way analysis of variance (ANOVA) and used the Tukey's honest significant difference (HSD) post hoc test and SPSS version 22 (IBM Corp., Armonk, NY, USA). Statistical analysis was performed using GraphPad Prism version 3.03 (GraphPad Software, Inc.) The protein band intensity was quantified using Image J (25) (National Institutes of Health, Bethesda, MD, USA). P $<0.05$ was considered to indicate a statistically significant difference.

\section{Results}

Cowanin treatment reduces cell viability in LoVo cells. Initially, the antiproliferative activity of cowanin in LoVo cells was determined by MTT assay. LoVo cells were treated with cowanin at various concentrations $(0,5,10,15$ and $20 \mu \mathrm{g} / \mathrm{ml})$ for 3, 6, 9, 12 and $24 \mathrm{~h}$. Cowanin treatment reduced the cell viability in a time and dose-dependent manner (Fig. 1B), compared with the control cells. The $\mathrm{IC}_{50}$ of cowanin in the colorectal carcinoma LoVo cells was $11 \pm 0.50 \mu \mathrm{g} / \mathrm{ml}$. By contrast, the $\mathrm{IC}_{50}$ of cowanin in the normal cell line COS-7 was $23.21 \pm 1.73 \mu \mathrm{g} / \mathrm{ml}$ (Fig. 1C). Morphology changes of the LoVo cells treated with cowanin were examined by microscopy. Following treatment with $15 \mu \mathrm{g} / \mathrm{ml}$ cowanin, LoVo cells 
A
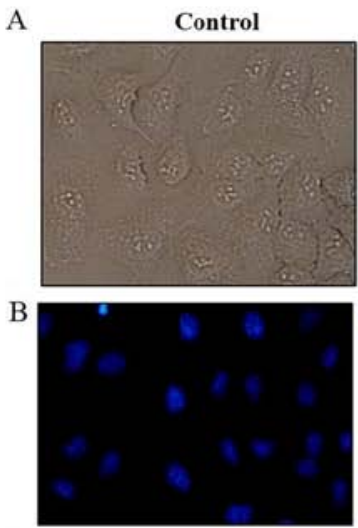

$\mathrm{C}$
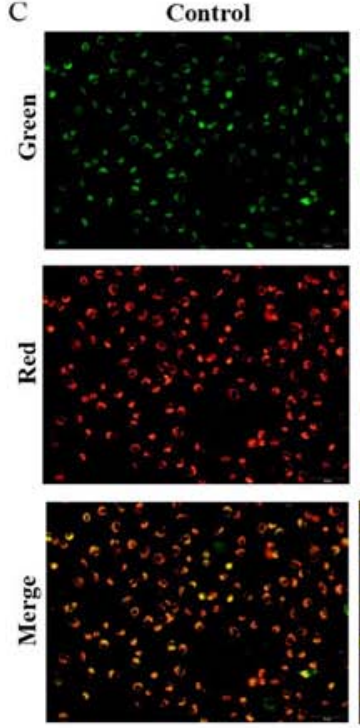

D

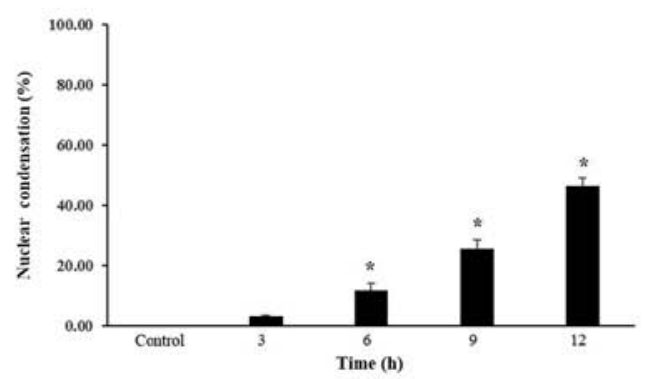

$6 \mathrm{~h}$
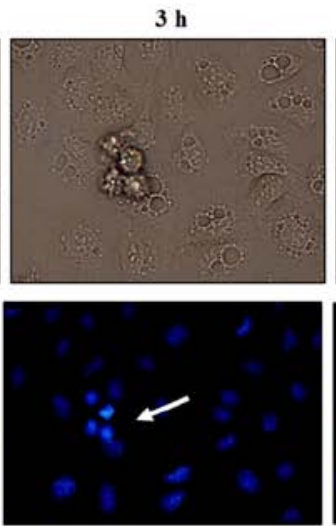

$3 \mathrm{~h}$
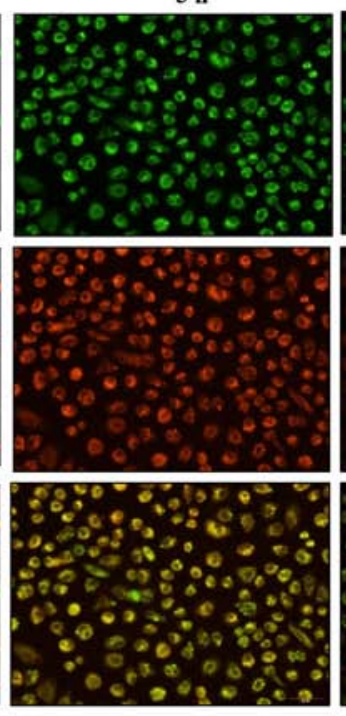

Time (h)

$6 \mathrm{~h}$
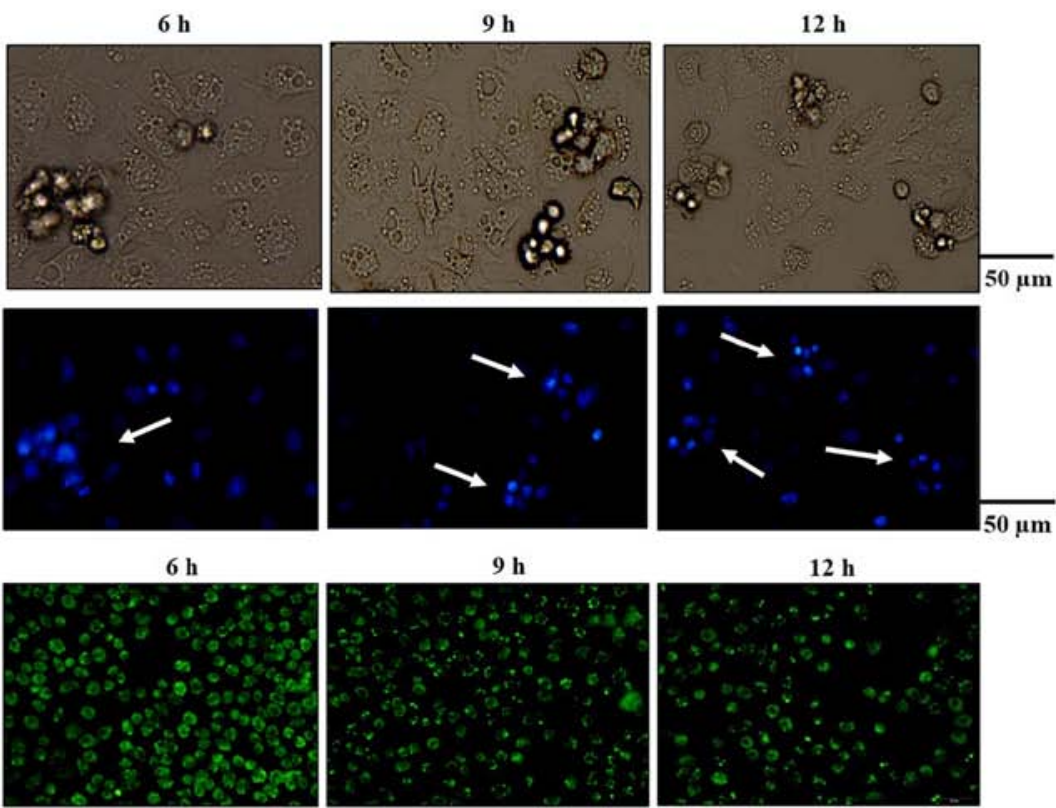

$9 \mathrm{~h}$
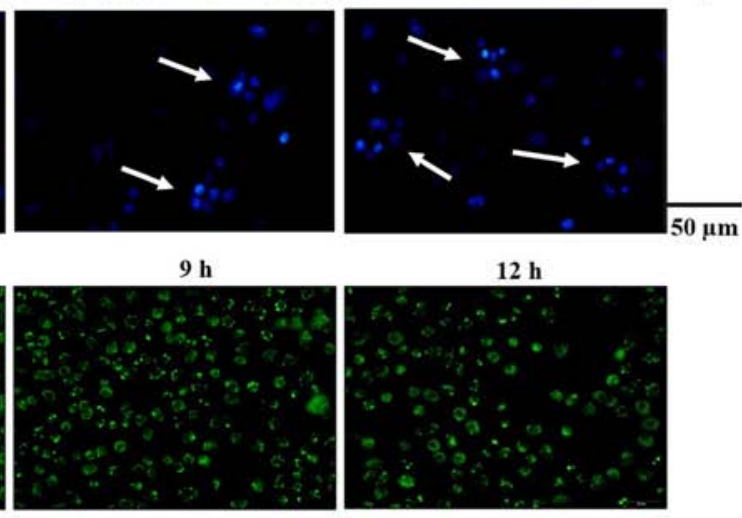

$12 \mathrm{~h}$
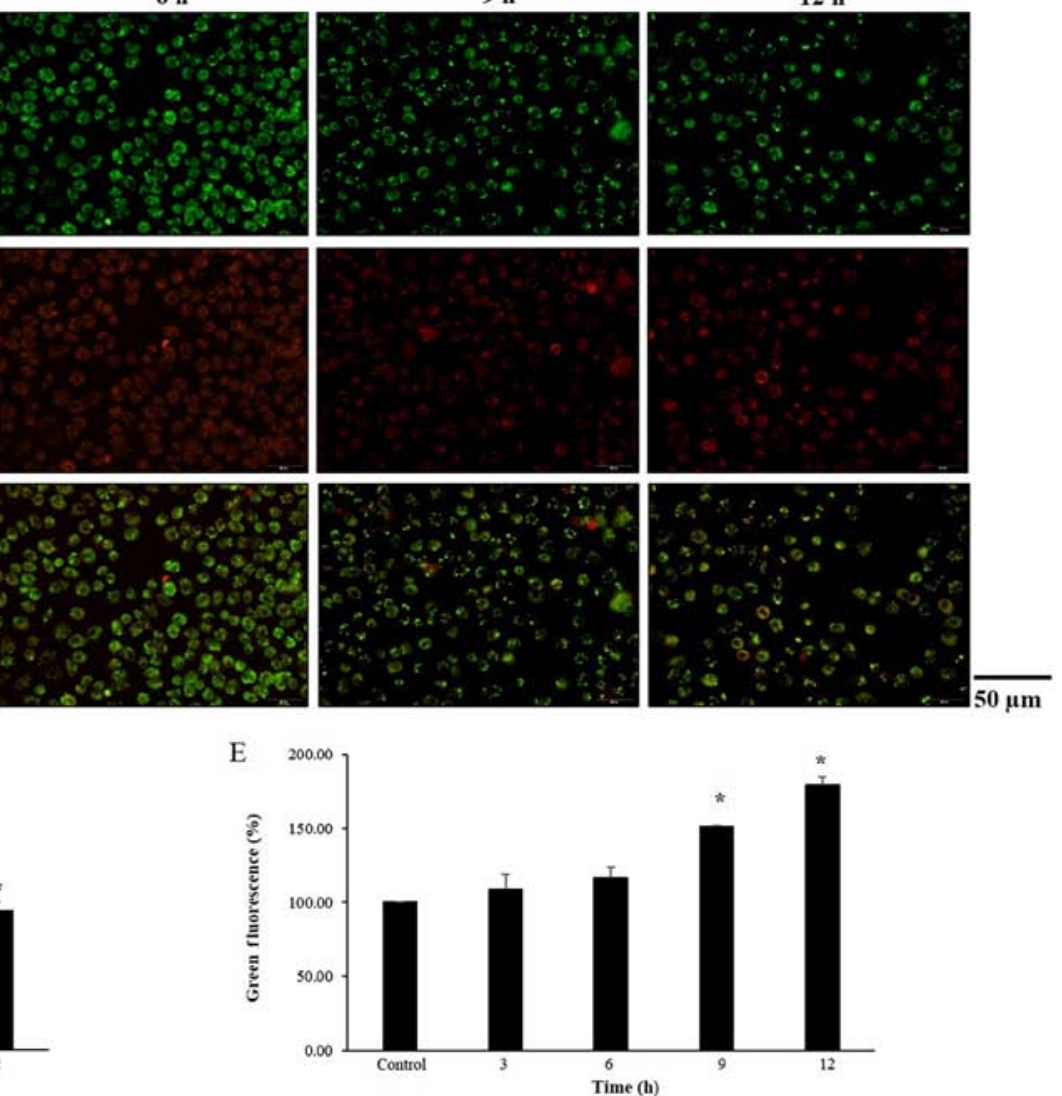

Figure 2. Effects of cowanin on nuclear condensation and mitochondrial membrane potential of LoVo cells. (A) Morphological changes of LoVo cells. LoVo cells were treated with cowanin for 3, 6, 9 and $12 \mathrm{~h}$. Cells treated with vehicle alone (DMSO) were used as control. (B) LoVo cells were stained with Hoechst 33342 and stained nuclei were examined under a fluorescent microscope (x40 magnification). White arrows indicate the nuclear condensation of LoVo cells. (C) Cells were treated with $15 \mu \mathrm{g} / \mathrm{ml}$ cowanin for 3, 6, 9 and $12 \mathrm{~h}$, stained with JC-1 dye, and observed by fluorescence microscopy. Red fluorescence indicates high membrane potential, whereas green fluorescence indicates loss of membrane potential (x40 magnification). Cells treated with vehicle alone (DMSO) were used as control. (D) Quantification of \% cells exhibiting nuclear condensation as determined by Hoechst 33342 staining. (E) Quantification of $\%$ of cells exhibiting low membrane potential as evidenced by green fluorescence following JC-1 staining. ${ }^{*} \mathrm{P}<0.05$ compared with control.

exhibited round morphology with cell shrinkage and nuclear condensation, suggesting cowanin-induced apoptosis in LoVo cells (Fig. 2A).

Effect of cowanin on nuclei changes. To determine whether the antiproliferative activity of cowanin was associated with apoptosis, LoVo cells were stained with Hoechst 33342 following exposure to cowanin and observed under a fluorescence microscope. The results demonstrated that cowanin treatment induced significantly increased nuclear condensation in LoVo cells at 3, 6, 9 and $12 \mathrm{~h}$ compared with control cells
(Fig. 2B and D), suggesting that cowanin induced apoptosis in a time-dependent manner.

Effect of cowanin on mitochondria membrane potential $(\Delta \Psi \mathrm{m})$ of LoVo cells. To determine the association of mitochondrial membrane potential and apoptosis, LoVo cells were stained with the JC-1 dye following exposure to cowanin and observed under a fluorescence microscope. Representative images of JC-1 staining are illustrated in Fig. 2C, where mitochondrial depolarization is indicated by a decrease in the red/green fluorescence intensity ratio. The results demonstrated that, while 
A
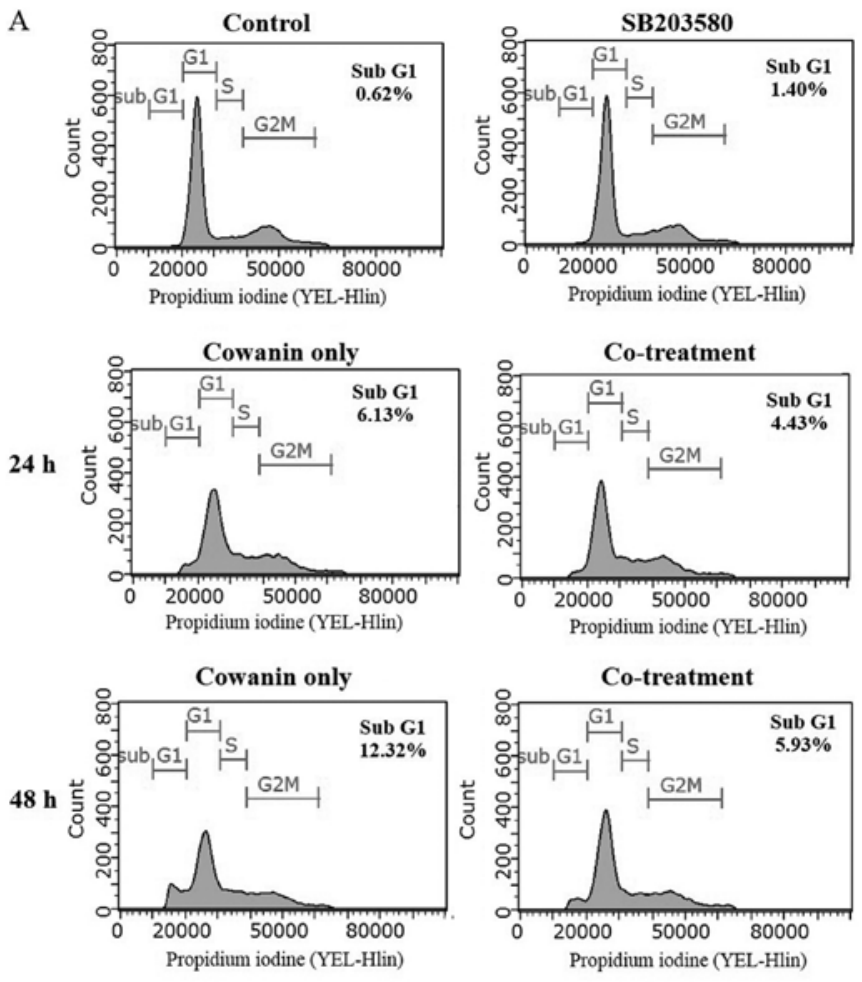

B

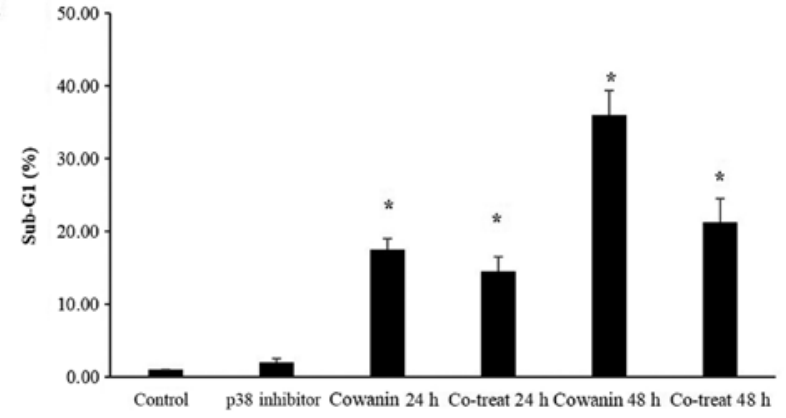

Figure 3. Cell cycle phase distribution of LoVo cells treated with cowanin. LoVo cells were treated with vehicle alone (control), treated with cowanin alone, or treated with a combination of SB203580 and cowanin. Cell cycle phase distribution was examined by flow cytometry and the ratio of cells in the sub-G1 peak was calculated. (A) Representative plots for each experimental group. (B) Quantification of \% of cells in the sub-G1 peak in each experimental group. ${ }^{*} \mathrm{P}<0.05$ compared with control

the control untreated LoVo cells exhibited predominantly red fluorescence, cells treated with cowanin exhibited increased green fluorescence (Fig. 2C and E), indicating that cowanin induced a low mitochondrial membrane potential. These results suggested that cowanin induced apoptosis by reducing the mitochondria membrane potential of LoVo cells in a time-dependent manner.

Effect of cowanin on cell cycle distribution. The effect of cowanin on the cell cycle phase distribution of the LoVo cells was detected by flow cytometry. The results demonstrated that treatment with $15 \mu \mathrm{g} / \mathrm{ml}$ cowanin increased the $\%$ of cells in the sub-G1 phase from $0.62 \%$ in the control cells to 6.13 and $12.32 \%$ following 24 and 48-h treatment, respectively (Fig. 3A and B). Of note, combination of SB203580 and cowanin treatments decreased the sub-G1 population to 4.43 and $5.93 \%$ following 24 and 48 h, respectively (Fig. 3A and B). These results indi-
A
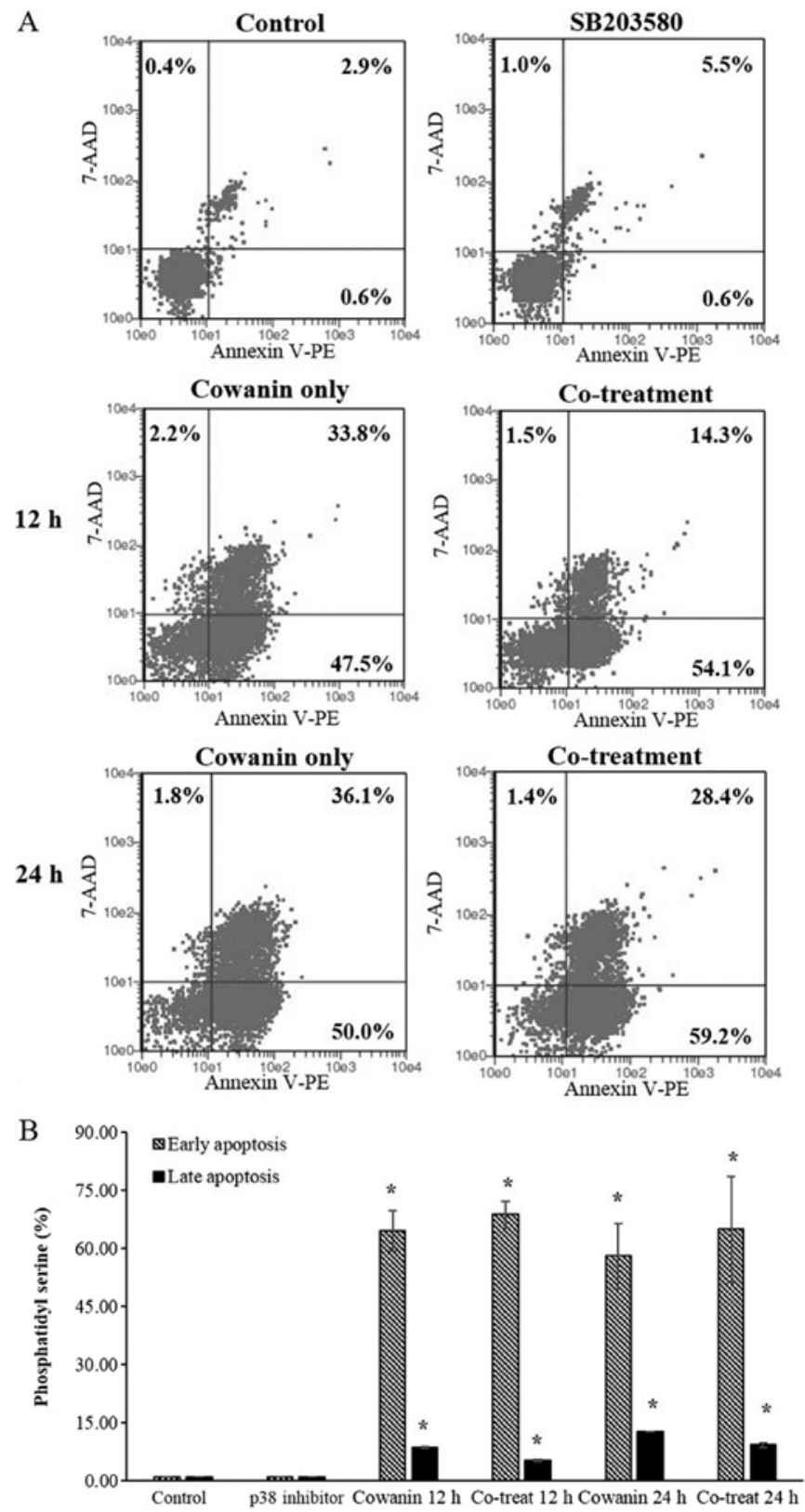

Figure 4. Flow cytometry analysis of phosphatidyl-serine exposure in LoVo cells. LoVo cells were treated with vehicle alone (control), treated with cowanin alone, or treated with a combination of SB203580 and cowanin for 12 and 24 h. (A) Representative dot plots of Annexin V-PE staining. The lower left quadrants represent the viable cells, the lower right quadrants the early apoptotic cells, the upper right quadrants the late apoptotic cells, and the upper left quadrants the necrotic cells. (B) Quantification of the \% of early apoptotic cells and late apoptotic cells at 12 and $24 \mathrm{~h}$ in each experimental group. ${ }^{*} \mathrm{P}<0.05$ compared with control. $\mathrm{PE}$, phycoerythrin; 7-AAD, 7-Aminoactinomycin D.

cated that SB203580 blocked the cowanin-induced apoptosis in LoVo cells.

Effect of cowanin on phosphatidyl-serine exposure. The effect of cowanin on phosphatidyl-serine was detected by flow cytometry. The results demonstrated that treatment with $15 \mu \mathrm{g} /$ $\mathrm{ml}$ cowanin increased the \% of early apoptotic LoVo cells to 47.5 and $50.0 \%$ and of late apoptotic LoVo cells to 33.8 and $36.1 \%$ following 12 - and 24-h treatment, compared with 0.6 and $2.9 \%$ respectively in the control group (Fig. 4A and B). By 
A
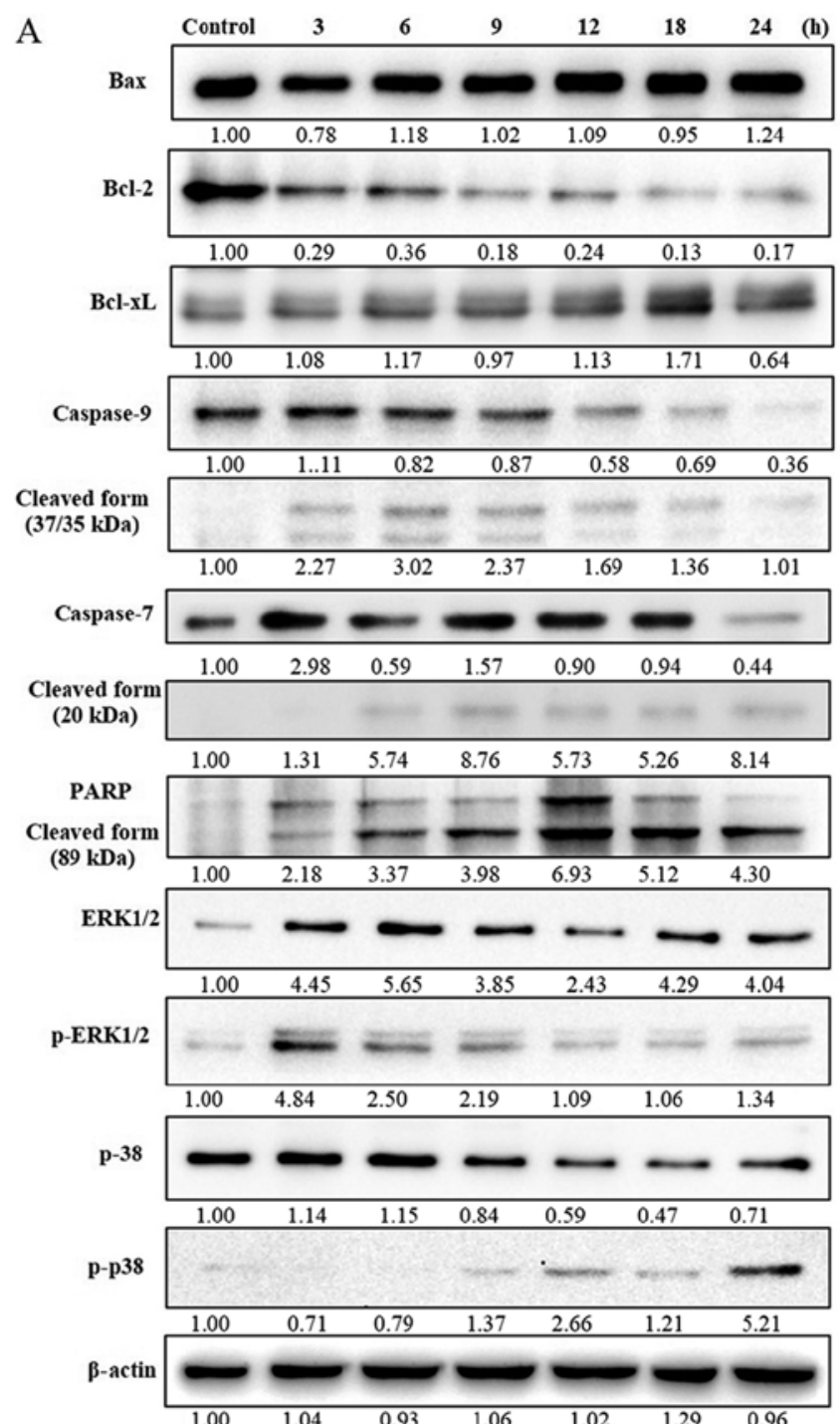
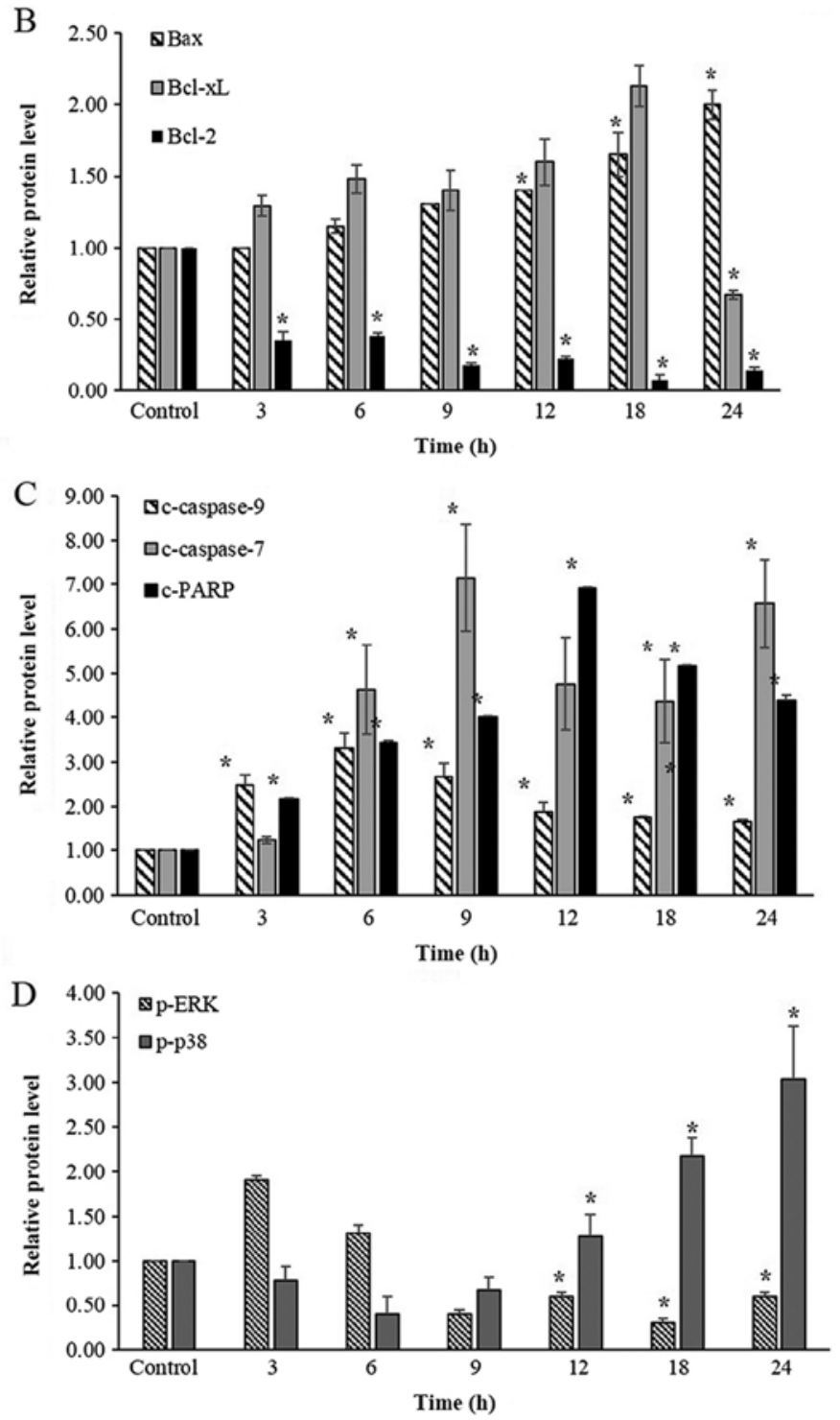

Figure 5. Effect of cowanin on the expression of Bcl-2 family proteins in LoVo cells. LoVo cells were treated with $15 \mu \mathrm{g} / \mathrm{ml}$ cowanin for 3, 6, $9,12,18$ and $24 \mathrm{~h}$. Cells treated with vehicle alone (DMSO) were used as control. (A) Effect of cowanin on Bcl-2 family proteins, cleaved caspase-9, cleaved caspase-7, cleaved PARP, p-ERK1/2 and p-p38 expression was examined by western blot analysis. (B) Cowanin-treated cells displayed significantly increased Bax expression and decreased Bcl-2 and Bcl-xL expression compared with control in a time-dependent manner. (C) Cowanin-treated cells displayed a significant increase in cleaved caspase-9 and -7 compared with control. (D) Cowanin-treated cells exhibited a significant decrease in ERK and p38 phosphorylation compared with control. "P<0.05 compared with control. Bcl-2, BCL2 apoptosis regulator; PARP, poly-ADP-ribose-polymerase; p-, phosphorylated; ERK, extracellular signal-regulated kinase; Bax, BCL2 associated X; Bcl-xL, BCL2 extra-large.

contrast, the combination treatment of SB203580 and cowanin decreased the $\%$ of late apoptotic LoVo cells to 14.3 and $28.4 \%$ following 12- and 24-h treatment, respectively, compared with the cowanin treatment alone (Fig. $4 \mathrm{~A}$ and $\mathrm{B}$ ). These results indicated that SB203580 blocked the cowanin-induced apoptosis in LoVo cells via decreasing the \% of late apoptotic LoVo cells.

Effect of cowanin on the expression of apoptosis-related proteins. The Bcl-2 family of proteins is involved in the regulation of apoptotic cell death (26). The Bcl-2 family consists of antiapoptotic proteins, such as Bcl-2 and BCL2 extra-large (Bcl-xL), and proapoptotic proteins, such as Bax, Bak and caspases (27), thus it is an important mediator of the apoptosis pathway (28). To determine whether cowanin induced apoptosis through the intrinsic pathway (mitochondrial apoptosis pathway), the expression levels of $\mathrm{Bcl}-2$ family proteins were examined following cowanin treatment by western blot analysis. Cowanin treatment decreased Bcl- 2 expression at $3 \mathrm{~h}$, while it increased Bax expression at $6 \mathrm{~h}$ (Fig. 5A and B). These results indicated that cowanin induced apoptosis through the intrinsic pathway.

Furthermore, the expression of total and active cleaved caspases was examined following cowanin treatment by western blot analysis. As illustrated in Fig. 5A and C, cowanin increased caspase- 9 and caspase-7 cleavage following 3 and $6 \mathrm{~h}$ of treatment, as well as increased cleaved-PARP expression. Thus, cowanin-induced apoptosis was mediated by caspase-7 and was associated with the activation of the intrinsic pathway via caspase-9. 

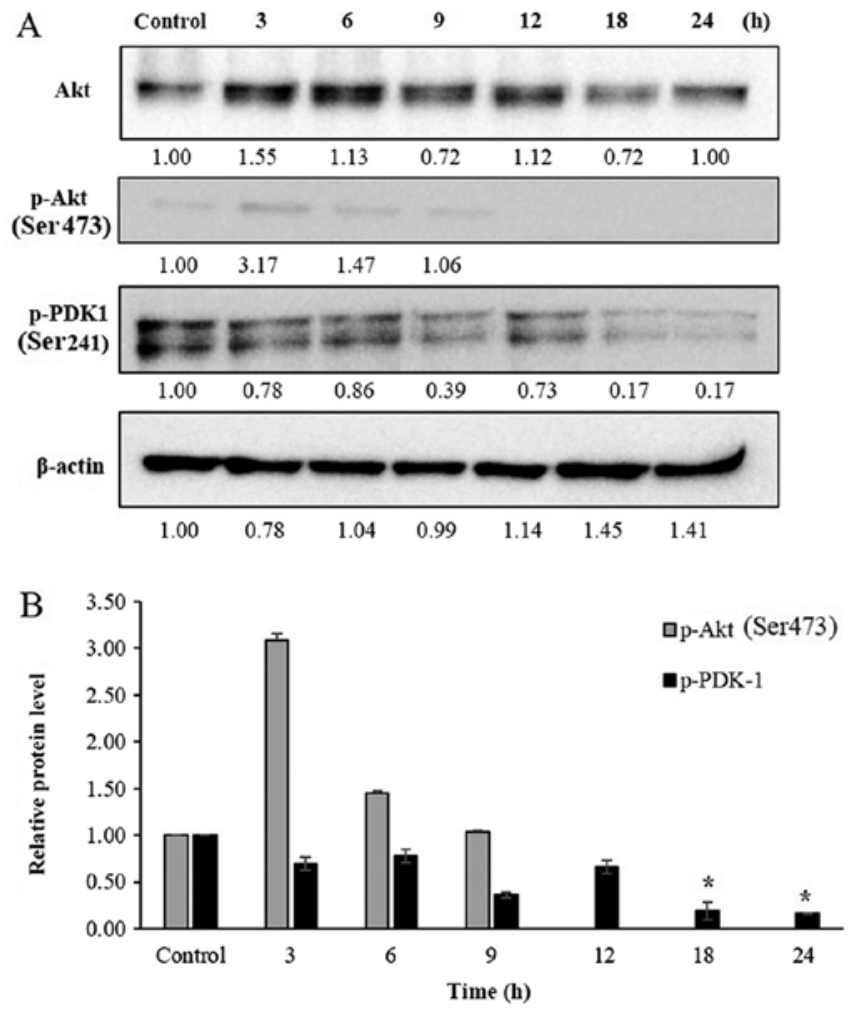

Figure 6. Effect of cowanin on Akt signaling in LoVo cells. LoVo cells were treated with $15 \mu \mathrm{g} / \mathrm{ml}$ cowanin for $3,6,9,12,18$ and $24 \mathrm{~h}$. Cells treated with vehicle alone (DMSO) were used as control. (A) Expression of total Akt, p-Akt and p-PDK1 protein levels were determined in LoVo cells by western blot analysis. $\beta$-actin was used as the internal control. (B) Cowanintreated cells displayed significantly decreased p-Akt (Ser473) and p-PDK1 expression in a time-dependent manner. ${ }^{*} \mathrm{P}<0.05$ compared with control. Akt, AKT serine/threonine kinase 1; p-, phosphorylated; PDK1, 3-phosphoinositide-dependent protein kinase-1.

Effect of cowanin on MAPK signaling. Members of the MAPK pathway, including ERK, JNK and p38, have been reported to serve important roles in cell proliferation and death (29). JNK and p38 are activated by inflammatory cytokines, heat shock and ultraviolet light, mediating growth arrest and inducing cell apoptosis, while ERK promotes cell survival (11). In the present study, cowanin was demonstrated to upregulate the phosphorylation of ERK, as evidence by the increased levels of p-ERK at $3 \mathrm{~h}$ compared with the control (Fig. 5A and D). However, p-ERK was significantly decreased at $6 \mathrm{~h}$ and at later times points of cowanin treatment (Fig. 5A and D). As previously reported, ERK may have dual roles as a cellular adaptive response during the initial phase and as a cytotoxic response during the later stages of drug-induced stress (30). The phosphorylation of ERK indicated two peaks: at the early phase and at the last phase (31). Furthermore, cowanin was demonstrated to upregulate the phosphorylation of $\mathrm{p} 38$ at 9, 12, 18 and $24 \mathrm{~h}$ following cowanin treatment compared with the control (Fig. 5A and D). The results indicated that cowanin induced LoVo cell apoptosis via the MAPK signaling pathway, by downregulating the phosphorylation of ERK and by upregulating the phosphorylation of $\mathrm{p} 38$.

Effect of cowanin on Akt signaling. The Akt pathway is important in the development of cancer. This pathway has
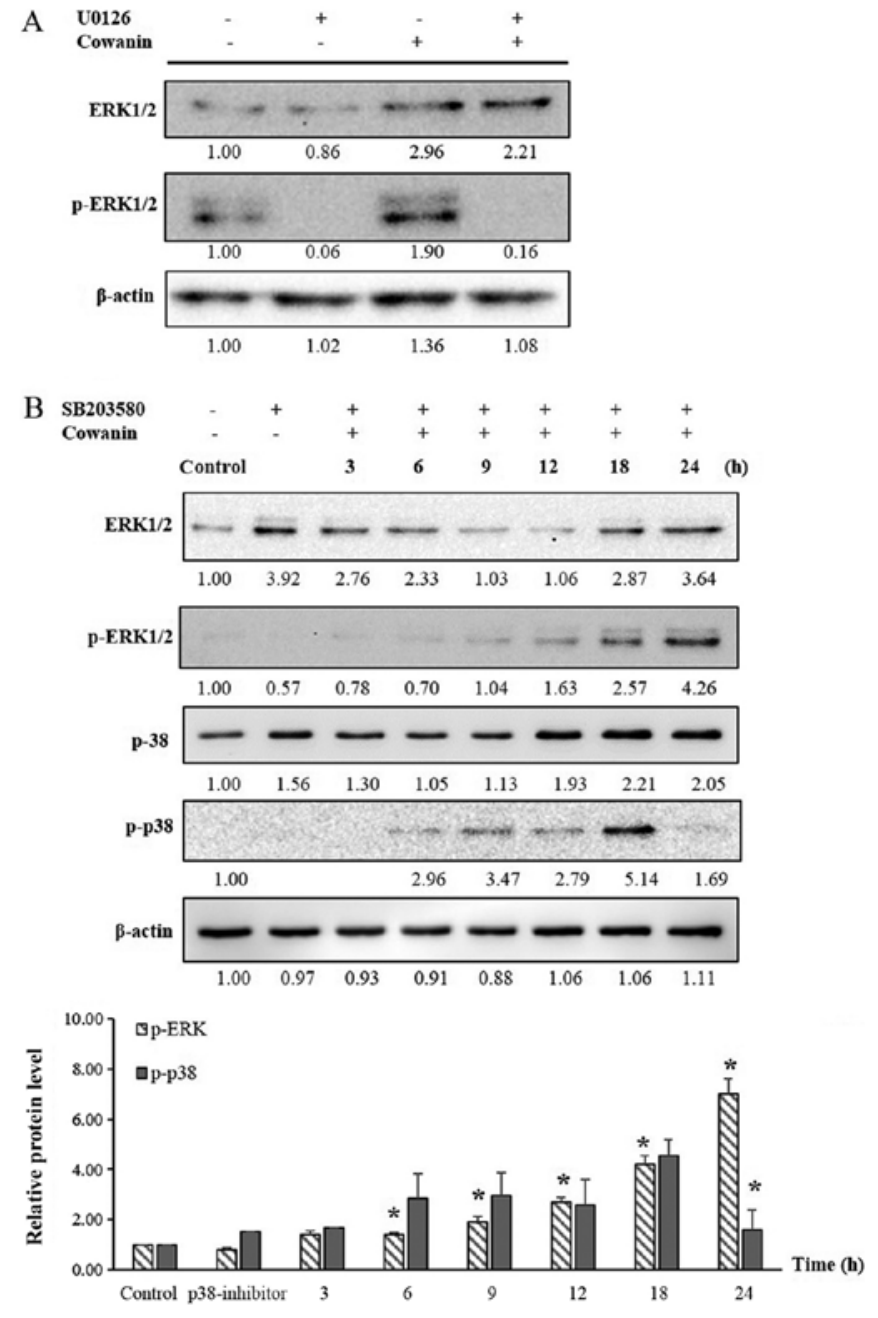

Figure 7. Effect of U0126 and SB203580 on MAPK signaling in LoVo cells Cells were pre-treated with (A) U0126 (50 $\mu \mathrm{M}$ for $24 \mathrm{~h}$ ) or (B) SB203580 (10 $\mu \mathrm{M}$ for $1 \mathrm{~h})$, then treated with $15 \mu \mathrm{g} / \mathrm{ml}$ cowanin, and examined by western blot analysis. $\beta$-actin was used as the internal control. ${ }^{*} \mathrm{P}<0.05$ compared with control. MAPK, mitogen-activated protein kinase; ERK, extracellular signalregulated kinase; p-, phosphorylated.

an important role in multiple cellular functions, including proliferation, adhesion, migration, invasion, metabolism, cell survival and protein synthesis. Akt is activated by phosphorylation at Thr308 and Ser473 in the plasma membrane (32). The results of the present study demonstrated that cowanin treatment decreased phosphorylation of Akt (Ser473) following $9 \mathrm{~h}$ of treatment, and also decreased phosphorylation of PDK1 at Ser241 following $9 \mathrm{~h}$ of treatment, compared with the control (Fig. 6A and B). Cowanin treatment did not markedly affect total Akt protein compared with the control group. These results demonstrated that cowanin inhibited LoVo cell survival via downregulation of Akt phosphorylation.

SB203580 (a p38 inhibitor) inhibits cell death. Therefore, the present study used U0126 (a MEK1/2 inhibitor) and SB203580 (a p38 inhibitor) to confirm that cowanin-induced apoptosis in LoVo cells occurred via the ERK and p38 signaling pathway. The results demonstrated that U0126 and SB203580 treatments blocked the effects of cowanin on ERK and p38 phosphorylation (Fig. 7A and B). These results indicated that cowanin inhibited cell survival through the p38 signaling pathway. Furthermore, the results demonstrated that 


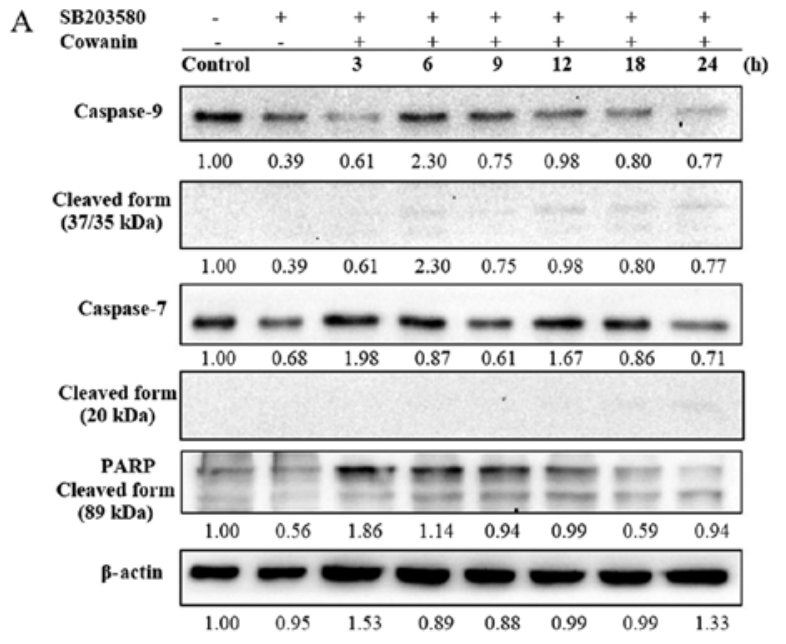

B

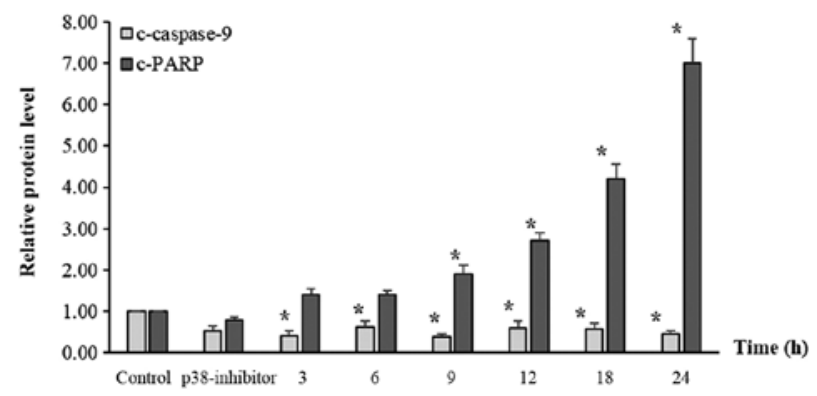

Figure 8. SB203580 inhibits cell death via the caspase signaling pathway. LoVo cells were pretreated with SB203580 $(10 \mu \mathrm{M}$ for $1 \mathrm{~h})$, then treated with $15 \mu \mathrm{g} / \mathrm{ml}$ cowanin for 3, 6, 9, 12, 18 and $24 \mathrm{~h}$. (A) Representative blots and (B) quantification of cleaved caspase-9, cleaved caspase-7 and cleaved PARP levels, as examined by western blot analysis. $\beta$-actin was used as the internal control. ${ }^{*} \mathrm{P}<0.05$ compared with control. PARP, poly-ADP-ribose-polymerase.

the combination of SB203580 and cowanin decreased cleaved caspase-9 and cleaved caspase-7 expression (Fig. 8A and B), which is in accordance with a previous report showing that the $\mathrm{p} 38$ inhibitor reduced cleaved caspase- 3 expression in MA-10 cells (33). In addition, the results demonstrated that the combination of SB203580 and cowanin increased p-ERK expression upon treatment for $9 \mathrm{~h}$. These results indicated that the combination of SB203580 and cowanin treatments blocked the cowanin-mediated LoVo cell apoptosis via the caspase signaling pathway.

\section{Discussion}

Colorectal cancer is one of the most prevalent and deadly types of cancer in both men and women worldwide. Approximately $90 \%$ of patients with metastatic colorectal cancer is resistant to chemotherapy, including resistance to epidermal growth factor receptor (EGFR) antagonists, while only $10 \%$ of patients exhibit a primary response to EGFR-targeted therapies, cetuximab or panitumumab (34). Thus, there is a need to discover more effective treatments with lower side effects for colorectal cancer treatment. In recent years, the discovery of novel cancer therapeutics in preclinical trials has turned to natural products with low toxicity and low drug resistance. Previous studies have reported that curcumol, a bioactive component of Zedoary oil isolated from Rhizoma curcumae, inhibits LoVo cell proliferation and induces apoptosis by increasing the phosphorylation of p38 MAPK (35). As colorectal cancer cells resistant to TRAIL-induced apoptosis remains a problem in the treatment of these cancers, it has been suggested that goniothalamin with TRAIL may have a potential to induce apoptosis via the death receptor-TRAIL mediated apoptosis pathway in LoVo cells (36). Larminarin extracted from Laminarin japonica induces apoptosis in human colorectal cancer LoVo cells via the mitochondrial pathway and by increasing ROS levels (37). In the present study, the anticancer effect of cowanin, extracted from G. cowa, was examined in LoVo cells. The results demonstrated that cowanin could inhibit cell growth in a time and dose-dependent manner, with $\mathrm{IC}_{50}$ of $11 \pm 0.50 \mu \mathrm{g} / \mathrm{ml}$.

Cell cycle is a process of replication and division of chromosomes within the nucleus occurring prior to cell division. During apoptosis, DNA is degraded by cellular endonucleases resulting in less DNA compared with healthy cells, thus representing the sub-G1 peak in flow cytometry analysis $(38,39)$. The present results demonstrated that cowanin-treated LoVo cells had an increased sub-G1 population compared with control cells. Phosphatidyl-serine is a component of the cell membrane, and its exposure on the cell surface is regarded as a hallmark of apoptosis (40). In apoptotic cells, phosphatidyl-serine is translocated from the inner to the outer leaflet of the plasma membrane. Annexin V staining and flow cytometry were used for the detection of phosphatidyl-serine externalization. The results indicated that cowanin-treated LoVo cells had an increased ratio of early and late apoptotic cells in a time-dependent manner, compared with control cells. The present findings suggested that cowanin induced apoptosis, by inducing morphological changes, reducing mitochondrial membrane potential, increasing the sub-G1 population and increasing the ratio of early and late apoptotic cells in LoVo cells.

To confirm apoptosis, characteristic morphological changes, such as membrane blebbing, cell shrinkage, chromatin condensation and apoptotic bodies, were investigated by Hoechst 33342 staining. The results exhibited chromatin condensation and nuclei fragmentation following treatment with cowanin for 3, 6 , 9 and $12 \mathrm{~h}$ in LoVo cells. In addition, changes in mitochondrial membrane potential by JC-1 staining confirmed that cowanin induced apoptosis. Consistent with the loss of mitochondrial membrane potential, cells released proapoptotic proteins from mitochondria to cytosol and induced apoptosis by activation of caspase-9 and caspase-3/7 (38).

The apoptotic signaling pathways consist of two pathways, the extrinsic and the intrinsic pathway. The present results demonstrated that cowanin-treated LoVo cells had increased Bax expression but decreased Bcl-2 expression. In addition, cowanin increased cleaved caspase-9 (initiator caspase), -7 (effector caspase) and cleaved-PARP expression. In the caspase cascade, caspase- 9 causes the activation of caspase-7, which then cleaves vital substrates, such as PARP, that play a vital role in DNA repair (41). The present results indicated that cowanin induced apoptosis via the mitochondrial pathway. As Bcl-2 is an antiapoptotic protein which binds with Bax and Bak to protect mitochondrial damage, the present results demonstrated that cowanin treatment decreased Bcl-2, leading to mitochondrial dysfunction and apoptosis (42).

Akt a serine/threonine kinase is a central mediator of the phosphoinositide 3-kinase (PI3K) pathway. Akt stimulates protein synthesis and cell growth by phosphorylation of 
mammalian target of rapamycin (mTOR). Akt also inhibits proapoptotic proteins, such as BCL2 associated agonist of cell death (Bad) and BCL2 like 11 (also known as Bim), and degrades the tumor suppressor p53 gene, thus enhancing cell survival. When PI3K activation occurs, phosphatidylinositol (3,4,5)-trisphosphate recruits Akt to the inner membrane, where PDK1 is located. The interaction of Akt with PDK1 prevents conformational changes in Akt. PDK1 activates Akt by phosphorylation of Thr308 and Ser473 (43). Activated Akt regulates numerous cellular functions, including angiogenesis, cell proliferation, cell survival, cell metabolism and protein synthesis. The phosphorylation of proapoptotic proteins, such as Bad and procaspase-9, inhibits Akt activation (44). The present results demonstrated that cowanin-treated LoVo cells had decreased phosphorylation of Akt at Ser473 and of PDK1, indicating that cowanin treatment inhibited cell survival via the Akt signaling pathway in LoVo cells.

In addition, the present study investigated the effect of cowanin on the MAPK pathway. Members of the MAPK family of kinases, including ERK, JNK and p38, are reported to have important roles in cell proliferation and death (30). ERK is activated by growth factors and serves a role in cell proliferation, differentiation or survival, whereas JNK and p38 are activated by inflammatory cytokines, heat shock and ultraviolet light, and mediate growth arrest and apoptosis (11). In the present study, cowanin was demonstrated to upregulate phosphorylation of p38 and downregulate phosphorylation of ERK1/2. The results indicated that cowanin induced cell death in LoVo cells via the MAPK pathway by upregulating p38 phosphorylation in a time-dependent manner. Previous studies have demonstrated that p38 is important for apoptosis induction in human breast cancer and colon cancer cells $(45,46)$ The present study also confirmed the effect of SB203580, a widely used p38 inhibitor (47), on p38 phosphorylation. SB203580 inhibits phosphorylation and activation of Akt (48) and represents one of the most widely used therapies against inflammation (14). The present results demonstrated that SB203580 inhibited the phosphorylation of p38 in LoVo cells. Notably, the results revealed that combination of SB203580 and cowanin inhibited cell death in LoVo cells by decreasing cleaved capase- 9 and cleaved caspase-7 expression. Furthermore, the combination treatment upregulated the phosphorylation of ERK1/2. In addition, the combination treatment decreased the ratio of cells in the sub-G1 phase of the cell cycle, and decreased the ratio of late apoptotic cells, compared with cowanin-treated LoVo cells only. Thus, the present results suggested that SB203580 significantly blocked the cowanin-induced LoVo cell apoptosis. These results are in accordance with previous studies reporting that p38 inhibitor inhibited apoptosis by decreasing cleaved caspase-3 in MA-10 cells treated with cordycepin (33). Similarly, Junn and Mouradian (49) reported that SB203580 blocked caspase- 9 and activated caspase- 3 in dopamineinduced apoptosis in the SH-SY5Y neuroblastoma cell line, while Ma et al (50) reported that SB203580 decreased myocardial apoptosis and improved post-ischemic cardiac function.

In conclusion, the present study demonstrated for the first time that cowanin treatment inhibited cell proliferation and induced apoptosis in colorectal LoVo cells, via intrinsic or mitochondria pathway activation. In addition, cowanin downregulated ERK and Akt signaling and upregulated p38 MAPK signaling. SB203580 (a p38 inhibitor) pretreatment hindered the cowanin-induced apoptosis via the caspase signaling pathway. These findings suggested that cowanin may have a potential clinical application in the treatment of human colorectal cancer.

\section{Acknowledgements}

The authors would like to thank the Research unit in biological activities of bioactive compounds, and the Strategic Wisdom and Research Institute, Srinakharinwirot University for providing the materials and the cell culture room.

\section{Funding}

This study was supported by the Royal Golden Jubilee (RGJ) Ph.D. Program (grant no. PHD/0143/2553) from the Thailand Research Fund (TRF).

\section{Availability of data and materials}

The analyzed datasets generated during the study are available from the corresponding author on reasonable request.

\section{Authors' contributions}

NC performed the biological assays and drafted the manuscript; SN performed some biological assays; SL prepared the cowanin for use in the experiments; CT performed some biological assays; and RW was the principal investigator, and designed the experiment and approved the final manuscript. All authors have read and approved the final manuscript.

\section{Ethics approval and consent to participate}

Not applicable.

\section{Consent for publication}

Not applicable.

\section{Competing interests}

The authors declare that they have no competing interests.

\section{References}

1. Siegel R, Ma J, Zou Z and Jemal A: Cancer statistics, 2014. CA Cancer J Clin 64: 9-29, 2014.

2. Ferlay J, Soerjomataram I, Dikshit R, Eser S, Mathers C, Rebelo M, Parkin DM, Forman D and Bray F: Cancer incidence and mortality worldwide: Sources, methods and major patterns in GLOBOCAN 2012. Int J Cancer 136: E359-E386, 2015.

3. Lohsiriwat V, Lohsiriwat D and Thavichaigarn P; Society of Colon and Rectal Surgeons Thailand: Colorectal cancer screening and surveillance: A survey among Thai general surgeons. Asian Pac J Cancer Prev 10: 467-470, 2009.

4. Khuhaprema T and Srivatanakul P: Colon and rectum cancer in Thailand: An overview. Jpn J Clin Oncol 38: 237-243, 2008.

5. Elmore S: Apoptosis: A review of programmed cell death. Toxicol Pathol 35: 495-516, 2007.

6. Yaoxian W, Hui Y, Yunyan Z, Yanqin L, Xin G and Xiaoke W: Emodin induces apoptosis of human cervical cancer HeLa cells via intrinsic mitochondrial and extrinsic death receptor pathway. Cancer Cell Int 13: 71, 2013. 
7. Wong RS: Apoptosis in cancer: From pathogenesis to treatment J Exp Clin Cancer Res 30: 87, 2011.

8. Portt L, Norman G, Clapp C, Greenwood M and Greenwood MT: Anti-apoptosis and cell survival: A review. Biochim Biophys Acta 1813: 238-259, 2011

9. Dhillon AS, Hagan S, Rath O and Kolch W: MAP kinase signalling pathways in cancer. Oncogene 26: 3279-3290, 2007.

10. Hanahan D and Weinberg RA: Hallmarks of cancer: The next generation. Cell 144: 646-674, 2011.

11. Sugino T, Nozaki K, Takagi Y, Hattori I, Hashimoto N, Moriguchi $\mathrm{T}$ and Nishida E: Activation of mitogen-activated protein kinases after transient forebrain ischemia in gerbil hippocampus. J Neurosci 20: 4506-4514, 2000.

12. Fang JY and Richardson BC: The MAPK signalling pathways and colorectal cancer. Lancet Oncol 6: 322-327, 2005

13. Porras A, Zuluaga S, Black E, Valladares A, Alvarez AM, Ambrosino C, Benito M and Nebreda AR: P38 alpha mitogenactivated protein kinase sensitizes cells to apoptosis induced by different stimuli. Mol Biol Cell 15: 922-933, 2004.

14. Genovese MC: Inhibition of $\mathrm{p} 38$ : Has the fat lady sung? Arthritis Rheum 60: 317-320, 2009.

15. Panthong K, Pongcharoen W, Phongpaichit S and Taylor WC: Tetraoxygenated xanthones from the fruits of Garcinia cowa. Phytochemistry 67: 999-1004, 2006.

16. na Pattalung P, Thongtheeraparp W, Wiriyachitra $\mathrm{P}$ and Taylor WC: Xanthones of Garcinia cowa. Planta Med 60: 365-368, 1994.

17. Poomipamorn S and Kumkong A: Edible Multipurpose Tree Species: Cha-Muang. Agriculture Federative Co-operation of Thailand Ltd. Printing, Bangkok, pp118-120, 1997 (In Thai).

18. Murakami A, Jiwajinda S, Koshimizu K and Ohigashi $\mathrm{H}$ : Screening for in vitro anti-tumor promoting activities of edible plants from Thailand. Cancer Lett 95: 139-146, 1995.

19. Ilham M, Yaday $M$ and Norhanom AW: Tumour promoting activity of plants used in malaysian traditional medicine. Nat Prod Sci 1: 31-42, 1995.

20. Likhitwitayawuid K, Phadungcharoen T, Mahidol C and Ruchirawat S: 7-O-methylgarcinone e from Garcinia cowa. Phytochemistry 45: 1299-1301, 1997.

21. Panthong K, Hutadilok-Towatana $\mathrm{N}$ and Panthong $\mathrm{A}$ Cowaxanthone $\mathrm{F}$, a new tetraoxygenated xanthone, and other antiinflammatory and antioxidant compounds from Garcinia cowa. Can J Chem 87: 1636-1640, 2009.

22. Wahyuni FS, Shaari K, Stanslas J, Lajis NH and Dachriyanus: Cytotoxic xanthones from the stem bark of Garcinia cowa Roxb. J Chem Pharm Res 7: 227-236, 2015.

23. Mahabusarakam W, Chairerk P and Taylor WC: Xanthones from Garcinia cowa Roxb. latex. Phytochemistry 66: 1148-1153,2005.

24. Ritthiwigrom T, Laphookhieo S and Pyne SG: Chemical constituents and biological activities of Garcinia cowa Roxb. Maejo Int J Sci 7: 212-231, 2013.

25. Schneider CA, Rasband WS and Eliceiri KW: NIH Image to ImageJ: 25 years of image analysis. Nat Methods 9: 671-675, 2012.

26. Nuñez G and Clarke MF: The Bcl-2 family of proteins: Regulators of cell death and survival. Trends Cell Biol 4: 399-403, 1994.

27. Gross A, MaDonnell JM and Korsmeyer SJ: BCL-2 family members and the mitochondria in apoptosis. Genes Dev 13: 1899-1911, 1999.

28. Ouyang L, Shi Z, Zhao S, Wang FT, Zhou TT, Liu B and Bao JK: Programmed cell death pathways in cancer: A review of apoptosis, autophagy and programmed necrosis. Cell Prolif 45: 487-498, 2012

29. Zhang W and Liu HT: MAPK signal pathways in the regulation of cell proliferation in mammalian cells. Cell Res 12: 9-18, 2002.

30. Nakagawa Y, Iinuma M, Naoe T, Nozawa Y and Akao Y: Characterized mechanism of alpha-mangostin-induced cell death: Caspase-independent apoptosis with release of endonuclease-G from mitochondria and increased miR-143 expression in human colorectal cancer DLD-1 cells. Bioorg Med Chem 15: 5620-5628, 2007.

31. Krajarng A, Nakamura Y, Suksamrarn S and Watanapokasin R: $\alpha$-Mangostin induces apoptosis in human chondrosarcoma cells through downregulation of ERK/JNK and Akt signaling pathway. J Agric Food Chem 59: 5746-5754, 2011.
32. Innajak S, Mahabusrakum W and Watanapokasin R Goniothalamin induces apoptosis associated with autophagy activation through MAPK signaling in SK-BR-3 cells. Oncol Rep 35: 2851-2858, 2016

33. Pan BS, Wang YK, Lai MS, Mu YF and Huang BM: Cordycepin induced MA-10 mouse Leydig tumor cell apoptosis by regulating p38 MAPKs and PI3K/AKT sihnaling pathways. Sci Rep 5: 1-17, 2015.

34. Hammond WA, Swaika A and Mody K: Pharmacologic resistance in colorectal cancer: A review. Ther Adv Med Oncol 8: 57-84, 2016.

35. Wang J, Huang F, Bai Z, Chi B, Wu J and Chen X: Curcumol inhibits growth and induces apoptosis of colorectal cancer LoVo cell line via IGF-1R and p38 MAPK pathway. Int J Mol Sci 16 19851-19867, 2015.

36. Sophonnithiprasert T, Nilwarangkoon S, Nakamura $Y$ and Watanapokasin R: Goniothalamin enhances TRAIL-induced apoptosis in colorectal cancer cells through DR5 upregulation and cFLIP downregulation. Int J Oncol 47: 2188-2196, 2015.

37. Ji YB, Ji CF and Zhang H: Laminarin induces apoptosis of human colon cancer LOVO cells through a mitochondrial pathway. Molecules 17: 9947-9960, 2012.

38. Cory S and Adams JM: The Bcl2 family: Regulators of the cellular life-or-death switch. Nat Rev Cancer 2: 647-656, 2002.

39. Krishan A: Rapid flow cytofluorometric analysis of mammalian cell cycle by propidium iodide staining. J Cell Biol 66: 188-193, 1975.

40. Rysavy NM, Shimoda LMN, Dixon AM, Speck M, Stokes AJ, Turner $\mathrm{H}$ and Umemoto EY: Beyond apoptosis: The mechanism and function of phosphatidylserine asymmetry in the membrane of activating mast cells. Bioarchitecture 4: 127-137, 2014.

41. Yu SW, Wang H, Poitras MF, Coombs C, Bowers WJ, Federoff HJ, PoirierGG, Dawson TM and Dawson VL: Mediation of poly(ADPribose) polymerase-1-dependent cell death by apoptosis-inducing factor. Science 297: 259-263, 2002

42. Wen X, Zhou J, Zhang D, Li J, Wang Q, Feng N, Zhu H, Song Y, $\mathrm{Li} \mathrm{H}$ and Bai C: Denatonium inhibits growth and induces apoptosis of airway epithelial cells through mitochondrial signaling pathways. Respir Res 16: 1-9, 2015

43. Stokoe D, Stephens LR, Copeland T, Gaffney PR, Reese CB Painter GF, Holmes AB, McCormick F and Hawkins PT: Dual role of phosphatidylinositol-3,4,5-trisphosphate in the activation of protein kinase B. Science 277: 567-570, 1997.

44. Fresno Vara JA, Casado E, de Castro J, Cejas P, Belda-Iniesta C and González-Barón M: PI3K/Akt signalling pathway and cancer. Cancer Treat Rev 30: 193-204, 2004.

45. Sabnis G, Schayowitz A, Goloubeva O, Macedo L and Brodie A: Trastuzumab reverses letrozole resistance and amplifies the sensitivity of breast cancer cells to estrogen. Cancer Res 69 1416-1428, 2009

46. Oskouian B, Sooriyakumaran P, Borowsky AD, Crans A, Dillard-Telm L, Tam YY, Bandhuvula P and Saba JD: Sphingosine-1-phosphate lyase potentiates apoptosis via p53- and p38-dependent pathways and is down-regulated in colon cancer. Proc Natl Acad Sci USA 103: 17384-17389, 2006.

47. Cuenda A, Rouse J, Doza YN, Meier R, Cohen P, Gallagher TF, Young PR and Lee JC: SB 203580 is a specific inhibitor of a MAP kinase homologue which is stimulated by cellular stresses and interleukin-1. FEBS Lett 364: 229-233, 1995.

48. Lali FV, Hunt AE, Turner SJ and Foxwell BMJ: The pyridinyl imidazole inhibitorSB203580 blocks phosphoinositide-dependent protein kinase activity, protein kinase B phosphorylation, and retinoblastoma hyperphosphorylation in interleukin-2-stimulated $\mathrm{T}$ cells independently of $\mathrm{p} 38$ mitogen-activated protein kinase. J Biol Chem 275: 7395-7402, 2000

49. Junn E and Mouradian MM: Apoptotic signaling in dopamine-induced cell death: The role of oxidative stress, p38 mitogen-activated protein kinase, cytochrome $c$ and caspases. J Neurochem 78: 374-383, 2001.

50. Ma XL, Kumar S, Gao F, Louden CS, Lopez BL, Christopher TA, Wang C, Lee JC, Feuerstein GZ and Yue TL: Inhibition of p38 mitogen-activated protein kinase decreases cardiomyocyte apoptosis and improves cardiac function after myocardial ischemia and reperfusion. Circulation 99: 1685-1691, 1999. 